\title{
The SAPHO Syndrome: A Single-center Study of 41 Adult Patients
}

\author{
Faisal Aljuhani, Anne Tournadre, Zuzana Tatar, Marion Couderc, Sylvain Mathieu, \\ Sandrine Malochet-Guinamand, Martin Soubrier, and Jean-Jacques Dubost
}

\begin{abstract}
Objective. The SAPHO syndrome (synovitis, acne, pustulosis, hyperostosis, osteitis) is a rare disease and only a few series have been published about it. We describe the experience of a rheumatology department with a focus on the therapeutic aspects.

Methods. All cases of SAPHO fulfilling the Benhamou criteria and seen between 1992 and 2013 in our unit were retrospectively included.

Results. Forty-one patients (11 men and 30 women) were included. The average age was 45 years (20-80 yrs) at the time of diagnosis. Nineteen patients had palmoplantar pustulosis, 3 had psoriasis vulgaris, 3 had severe acne, and 15 had no dermatological involvement. Bone symptoms involved mainly the anterior chest wall $(n=28,68 \%)$, followed by the spine $(n=16,39 \%)$ and sacroiliac joints $(\mathrm{n}=12,29 \%)$. Four patients had peripheral osteitis and 2 had mandibular osteitis. Ten patients had peripheral arthritis affecting mainly the knees and wrists. None of the 36 patients tested was HLA-B27-positive. At least a partial response was achieved with colchicine, methotrexate, or sulfasalazine in $0 / 6,2 / 4$, and $1 / 6$ of patients, respectively. Antibiotic therapy (azithromycin, $\mathrm{n}=7$; doxycycline, $\mathrm{n}=2$ ) was effective in $2 / 9$ patients. Pamidronate was prescribed in 26 patients with bone involvement and 18/22 patients evaluable at 6 months responded to this therapy. Two patients were treated with tumor necrosis factor blockers: 1 with infliximab and 1 with adalimumab, followed by etanercept.

Conclusion. Based on our experience, SAPHO can be diagnosed in the elderly. It was not associated with HLA-B27. Soft tissue involvement was common and the bisphosphonates were generally effective on bone involvement. (First Release Dec 15 2014; J Rheumatol 2015;42:329-34; doi:10.3899/jrheum.140342)
\end{abstract}

Key Indexing Terms:

SAPHO PALMOPLANTAR PUSTULOSIS SPONDYLOARTHRITIS BISPHOSPHONATE

SAPHO syndrome (synovitis, acne, pustulosis, hyperostosis, and osteitis) encompasses osteoarticular features, palmoplantar pustulosis, and severe acne ${ }^{1}$. Inflammatory osteitis with hyperostosis is the central feature of the syndrome and may occur in the absence of skin involvement. SAPHO includes entities previously described under various names, notably palmoplantar pustulosis or acne-related rheumatism, sternocostoclavicular hyperostosis, chronic relapsing multifocal osteomyelitis, which is more common in children, and sclerosing mandibular osteomyelitis $^{2}$. Its relationship with spondyloarthritis remains uncertain because the association with HLA-B27 is far weaker than was previously thought.

From the Department of Rheumatology, Gabriel Montpied Hospital, Centre Hospitalier Universitaire de Clermont-Ferrand, Clermont-Ferrand, France.

F. Aljuhani, MD; A. Tournadre, MD; Z. Tatar, MD; M. Couderc, MD;

S. Mathieu, MD; S. Malochet-Guinamand, MD; M. Soubrier, MD, PhD;

J-J. Dubost, MD; Department of Rheumatology, Gabriel Montpied

Hospital, Centre Hospitalier Universitaire de Clermont-Ferrand.

Address correspondence to Dr. J-J. Dubost, Service de Rhumatologie,

58, rue Montalembert, 63003 Clermont-Ferrand cedex 1, France.

E-mail: jjdubost@chu-clermontferrand.fr

Accepted for publication October 7, 2014.
SAPHO is a rare disease (with an estimated incidence of about 1/10,000) and few series have been published ${ }^{3,4,5}$. Differential diagnosis with infectious or neoplastic diseases may be difficult in case of isolated bone involvement. Therapeutic strategy is not well defined; many treatments have been proposed, including antibiotics to eradicate Propionibacterium acnes, a suspected causative agent, bisphosphonates when there is predominantly bone involvement, and various disease-modifying treatments, particularly methotrexate and biologics in refractory forms of the disease.

The aim of our study was to describe the clinical, biological, and radiological data in a cohort of patients diagnosed in the Department of Rheumatology at the Gabriel Montpied Hospital, France. In particular, HLA-B27 status, diagnostic difficulties, and treatments will be discussed.

\section{MATERIALS AND METHODS}

Our retrospective single-center study included all patients admitted to the Department of Rheumatology between 1992 and 2013 who met the SAPHO diagnostic criteria described by Benhamou, et $a l^{6}$.

The following information was collected: sex, age at the time of diagnosis, osteoarticular features [ribcage, spine, sacroiliac (SI) joints, long

Personal non-commercial use only. The Journal of Rheumatology Copyright @ 2015 . All rights reserved. 
bones, mandible, arthritis], and skin features (type of lesion and time of onset). Biological data were recorded [erythrocyte sedimentation rate (ESR), C-reactive protein (CRP), and HLA-B27 phenotype], together with imaging results [radiography, computed tomography (CT), magnetic resonance imaging (MRI), and bone scintigraphy] and biopsies when available. All treatments were recorded, including nonsteroidal antiinflammatory drugs (NSAID), disease-modifying treatments, corticosteroids, colchicine, local treatments, antibiotics, bisphosphonates, and tumor necrosis factor (TNF) blockers, as well as the physician's assessment of their efficacy. In addition, for bisphosphonates, response was also defined as at least $50 \%$ improvement in pain at 6 months.

Results were expressed as the mean \pm SD or the median with interquartile range for continuous data, and as the number of patients and associated percentages for categorical variables.

\section{RESULTS}

We identified 41 adult patients (40 white and 1 black; 11 men and 30 women) who met the criteria reported by Benhamou, et $a l^{6}$. Average age at diagnosis was $45 \pm 14$ years (range 20-80 yrs).

Cutaneous features. Nineteen patients had palmoplantar pustulosis (46\%), 3 had psoriasis vulgaris, 2 had severe acne, 1 had hidrosadenitis, and 1 patient had pyoderma. The cutaneous signs preceded the osteoarticular involvement in 11 patients (by more than $1 \mathrm{yr}$ in 6), occurred simultaneously in 7 , and developed afterward in 1 patient. Information was not available for 7 patients. Fifteen patients $(36 \%)$ had no skin involvement, although they had obvious hyperostosis on imaging.

Osteoarticular features. Anterior chest pain was the initial symptom in 12 patients, back pain in 11 patients, and buttock pain or sciatica in 6 . Two patients had scapular pain, 4 had knee and/or hand joint pains, and 1 had mandibular pain. Five patients had several symptoms involving both the ribcage and the spine.

The diagnosis delay was 12 months (6-66 mos) and median followup was 30 months (5.5-102 mos).

Bone scintigraphy was performed in 39/41 patients (95\%) to detect asymptomatic bone involvement. The average number of bone sites involved was 2 (range 0-6), the anterior chest wall being one of the sites. Five patients also had increased uptake in 1 or 2 peripheral joints. Twenty-four patients had a CT useful for better assessing osteitis and hyperostosis, and 22 patients had MRI because of spinal sites or peripheral osteitis and to assess soft tissue involvement.

The anterior chest wall was the most frequent localization (28/41 patients, 68\%). Affected sites were the sternoclavicular joints unilaterally or bilaterally with extension to the clavicle ( 22 patients), the first rib (5 patients), and the sternomanubrial joint (8 patients; Figure 1). Clinical symptoms were characterized by local pain and swelling. No cases of vascular compression were found.

Spine involvement was found in 16 patients (39\%), affecting thoracic spine in 10 patients with a total of 45 vertebrae, the lumbar spine in 8 patients (15 vertebrae), and cervical spine in 4 patients ( 8 vertebrae). One female patient had ascending thoracic involvement leading after a few months to a massive bridging from T3 to T12. Contiguous vertebrae were usually affected, although in some cases, distant sites were involved. Vertebral body involvement with sclerosis and the occasional reduction in height was the most common type of lesion. Paravertebral ossification may lead to vertebral blocks. Disc disease occurred variably. The appearances were more those of spondylitis in 10 patients and spondylodiscitis in 8 patients.

SI involvement was found in 12 patients (29\%) and was unilateral in 10 . This was characterized by severe osteosclerosis extending broadly over the iliac wing. Pubic symphysis involvement was found in 1 patient.

Unilateral mandibular involvement was found in 2 cases $(5 \%)$ and was isolated in 1 case (Figure 1).

Peripheral osteitis was found in 4 patients (10\%), affecting 1 bone in 3 patients ( 1 femur, 1 tibia, and 1 fibular) and 3 bones in 1 patient (femur, tibia, and fibular). A potentially severe periosteal reaction was usual.

Peripheral arthritis was found in 10 patients (24\%). Five patients had monoarthritis ( 3 wrists, 2 knees) combined with palmoplantar pustulosis (PPP) as the only feature for 2 patients. Four patients had oligoarthritis affecting a total of 3 knees, 4 wrists, and 1 hip, and 1 patient had polyarthralgia of the hands and feet. The disease was chronic in 9 patients. One patient had relapsing acute pseudoseptic monoarthritis occurring once or twice a year. Two patients had radiological carpitis with erosions.

Laboratory findings. A laboratory acute-phase reaction was present inconsistently. The ESR was $>20 \mathrm{~mm}$ at $1 \mathrm{~h}$ in $12 / 40$ patients $(30 \%$, highest value 94$)$ and CRP was $>5$ $\mathrm{mg} / \mathrm{l}$ in $21 / 40$ patients (53\%, highest value 143 ). In $8 / 40$ patients $(20 \%)$, leukocytosis was over 10,000 (highest value 16,000).

HLA-B27 was negative in the 36 patients tested.

Bone biopsies. A bone biopsy was performed in 9 patients to exclude infection or tumor. Histology revealed an aspecific osteitis in 6 patients and was normal in 3. In all cases, bacteriological study was negative.

Concomitant diseases. Two patients had anterior uveitis, which was recurrent in 1 patient. Two patients had a previous history of thyroiditis, 2 had a previous history of Sjögren syndrome, and 1 had idiopathic thrombocytopenic purpura. No patients had Crohn disease.

Treatment. All patients were treated with NSAID, which were inadequate or only transiently effective.

Eight patients had 1 or more corticosteroid injections, mostly in the knee, but also in the sternoclavicular, sternomanubrial, and SI joints. These were effective for variable periods of time. Only 2 patients received longterm oral corticosteroid therapy that produced incomplete improvement.

Personal non-commercial use only. The Journal of Rheumatology Copyright (c) 2015. All rights reserved. 


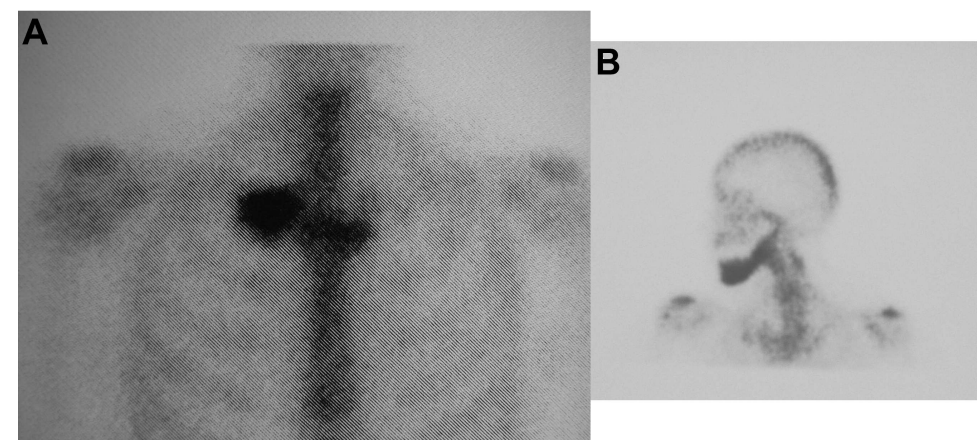

Figure 1. Scintigraphy. Increased uptake in the first right rib (A) and in the left mandible (B).

Colchicine was prescribed in 6 patients and was not effective. Six patients were treated with sulfasalazine. Only 1 patient achieved partial improvement of the joint involvement and greater improvement of the PPP. Methotrexate was given to 4 patients and was ineffective in 2 , partially effective in 1 , and effective on the polyarthralgia in 1 patient after 10 months of followup.

Antibiotics were used in 9 patients. Seven were treated with azithromycin ( 2 tablets per day for 3 days, then 2 tablets every 3 days for $5 \mathrm{mos}$ ). One patient achieved a good response, 1 partial response, and 5 patients did not improve. Two patients were treated with doxycycline $(100 \mathrm{mg}$ twice daily) that was ineffective in 1 patient and had to be stopped in the other because of intolerance.

Twenty-six patients were treated with pamidronate at a dose of $180 \mathrm{mg}$ per course. At 6 months, 22 patients were evaluable for response. In the physician's opinion, 18 patients responded to the treatment. Pain improved by at least $50 \%$ in $17 / 22$ patients and by $100 \%$ in $7 / 22$ (for a duration of at least $1 \mathrm{yr}$ in 5/7). Twelve patients had several courses. Seven patients developed a flu-like syndrome.

Two patients were treated with TNF blockers: 1 with infliximab that was rapidly effective and remained effective for 3 years; and 1 with adalimumab that switched to etanercept after 9 months, none of which was entirely effective.

\section{DISCUSSION}

Our series is consistent overall with other published series (Table 1). We found a female predominance with onset in middle age, although all ages were affected. Children were excluded from our study. The oldest patient was an 80-year-old woman who had ascending thoracic disease initially treated as tuberculous spondylodiscitis. Like the spondyloarthropathies, late onset can make the diagnosis difficult and infectious, or neoplastic diseases were initially considered in these patients, leading to invasive procedures. Therefore, age is not a sufficient argument to reject a diagnosis of SAPHO.

Skin involvement was absent in one-third of our patients, a frequency similar to that reported in other series (16-44\%). Severe acne or suppurative hidradenitis was only found in 3 patients (7\%) and was less common than in other series, possibly because the recruitment of patients was from a rheumatologic center.

The immediate diagnosis was correct when the predominant feature was anterior chest wall involvement. Thus, investigation for skin involvement and demonstration of osteitis and hyperostosis on imaging were sufficient to make the diagnosis. In some patients with initial symptoms in the spine, pelvic girdle, or long bones, identifying paucisymptomatic anterior chest involvement, particularly on bone scintigraphy, was helpful (Figure 1). Osteitis is sometimes associated with soft tissue involvement that could be suggestive of infection or neoplastic diseases, particularly lymphoma ${ }^{7,8}$. Spinal lesions can include paraspinal soft tissue involvement, suggestive of infection (Figure 2), but without abscess or severe epiduritis. Soft tissue involvement may also explain S1 sciatica because of extension to the first sacral foramen or nerve trunk involvement (Figure 3).

Osteitis is the central feature of the syndrome and was absent in 2 cases who, nevertheless, met the Benhamou, et $a l^{6}$ and Kahn and Khan criteria9. In 1 woman, the only feature for over 15 years was acute left knee monoarthritis recurring once or twice a year with palmoplantar pustulosis. NSAID and longterm antibiotic therapy were ineffective, and each episode was treated by a corticosteroid injection that was immediately effective. These cases of arthritis associated with PPP without bone involvement are well known and raise the problem of differential diagnostic with psoriatic arthritis ${ }^{10,11}$. Similar diagnostic problems are also encountered in cases of arthritis associated with severe acne. These isolated joint forms are now described in SAPHO series $^{10}$, although this trend could be the subject of further discussion when the new diagnostic criteria will be proposed.

The etiology of SAPHO syndrome is unknown, although an association with infection, particularly P. acnes, has been suggested ${ }^{12}$. Antibiotic therapy targeting this organism is occasionally effective, although relapses are reported when

Personal non-commercial use only. The Journal of Rheumatology Copyright @ 2015 . All rights reserved. 
Table 1. Characteristics of patients in cohort and in 3 European series. Values are $\%$ unless otherwise specified.

\begin{tabular}{|c|c|c|c|c|}
\hline Characteristics & $1974-1997^{3}, \mathrm{n}=120$ & $1984-2007^{5}, \mathrm{n}=52$ & $1990-2008^{4}, \mathrm{n}=71$ & $1992-2013, \mathrm{n}=41$ \\
\hline Age at diagnosis, yrs (range) & $38(5-67)$ & $42(15-73)$ & $45.5(35-54)$ & $45(20-80)$ \\
\hline Sex, female/male & $70 / 50$ & $26 / 26$ & $48 / 23$ & $30 / 11$ \\
\hline Anterior chest wall & 63 & 73 & 83 & 68 \\
\hline Spine & 33 & 19 & 66 & 39 \\
\hline Sacroiliac & 40 & 27 & 13 & 29 \\
\hline Peripheral arthritis & 36 & 32 & 28 & 24 \\
\hline Skin features & 84 & 63 & 80 & 64 \\
\hline Palmoplantar pustulosis & 55 & 51 & 60 & 46 \\
\hline Psoriasis vulgaris & 10 & 6 & 5 & 7 \\
\hline Acne & 18 & 39 & 19 & 5 \\
\hline Hidrosadenitis & - & - & 2 & 2 \\
\hline Sulfasalazine & 18 & 8 & $29 *$ & 15 \\
\hline Methotrexate & 8 & 13.5 & $29 *$ & 10 \\
\hline Corticosteroid therapy & 19 & 4 & 68 & 5 \\
\hline Bisphosphonate & 5 & 19 & 22.5 & 63 \\
\hline Anti-TNF & - & 2 & 13 & 5 \\
\hline
\end{tabular}

* Sulfasalazine, methotrexate, or leflunomide. NSAID: nonsteroidal antiinflammatory drug; TNF: tumor necrosis factor.

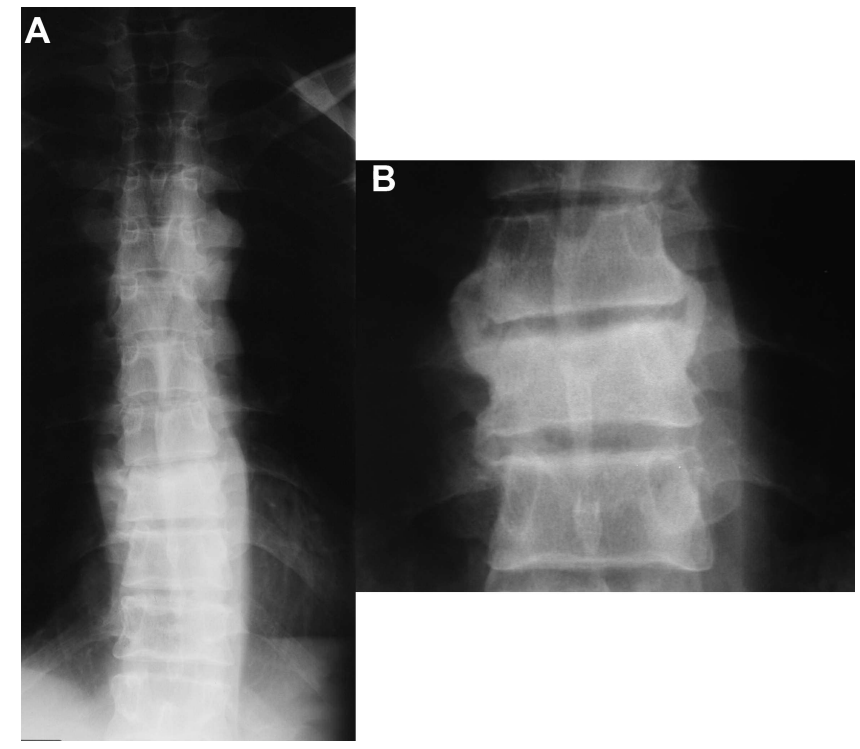

Figure 2. Thoracic spine radiograph. Osteosclerosis in T10 (A). Thickening of the soft tissue producing a spindle-like paravertebral appearance. (B) Large paravertebral staples.

treatment is stopped ${ }^{13}$. In our series, bacteriological studies were consistently negative and antibiotics were ineffective. This does not, however, exclude a mechanism of reactive osteitis analogous to reactive arthritis. SAPHO is occasionally included in the group of spondyloarthropathies ${ }^{14}$.
Supporting the link with spondyloarthritis are spinal, SI, and other joint involvement; association with psoriasis and inflammatory bowel diseases reported on several occasions $^{3,4,5}$ (but not in our series); and anterior uveitis noted in 2 cases in our series. However, consistent with other series, we did not find any association with HLA-B27 $7^{4,15}$. When SI disease was present, osteosclerosis extended well beyond the joint line (Figure 4), and in the spine, the whole vertebral body was also affected. Vertebral blocks could form and the paravertebral ossifications were different from syndesmophytes (Figures 2 and 5). SAPHO appears, above all, to be a distinct condition in which the fundamental lesion is inflammatory osteitis. Increased titers of some autoantibodies and an association with thyroiditis have been reported $^{4,16}$. It is interesting that there were 2 cases of thyroiditis, 2 cases of Sjögren syndrome, and 1 history of idiopathic thrombocytopenic purpura in our series, although no conclusions can be drawn from this. The existence of familial cases, which were not present in our series, similarities with animal models and with the PAPA (pyogenic arthritis, pyoderma gangrenosum, and acne) syndrome and Majeed syndrome, and the association with Crohn disease suggest that genetic factors play a role $2,4,17$.

Treatment is poorly defined, and to the best of our knowledge, no placebo-controlled trials are available. One specific feature of SAPHO compared to other rheumatic diseases is the use of bisphosphonates, particularly intra- 

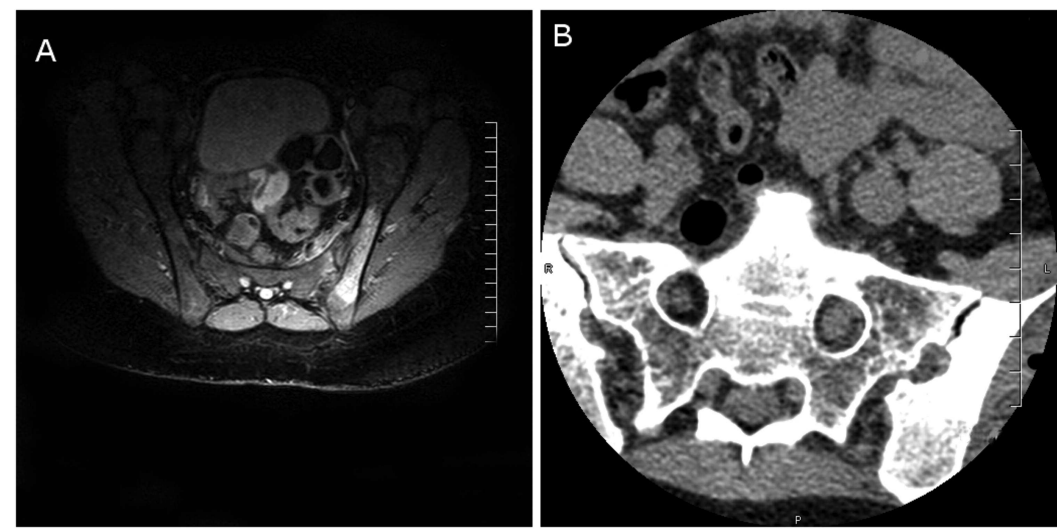

Figure 3. Sacral MRI (A) and CT (B). Inflammation of the soft tissues in front of the left sacroiliac joint, hypertrophy of the left S1 nerve root. MRI: magnetic resonance imaging; CT: computed tomography.

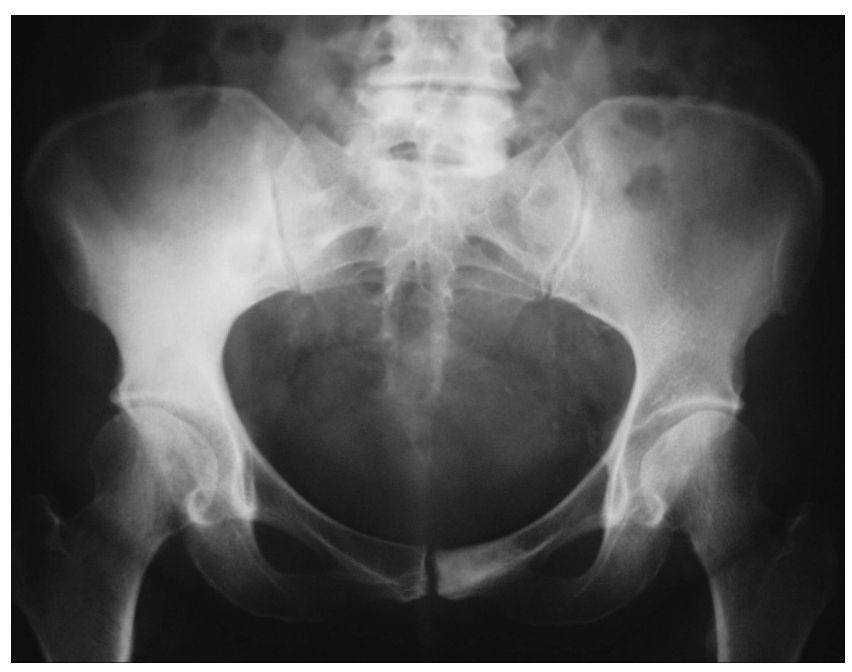

Figure 4. Pelvic radiography. Extensive osteosclerosis of the right iliac wing and left part of the pubic symphysis. venous pamidronate for the bone disease. Like others, we found a significant number of partial or complete sustained remissions over several months or even years ${ }^{18,19,20,21}$. We routinely use bisphosphonates in patients with bone involvement who do not respond to NSAID and corticosteroid injections. Biologics such as anti-TNF and anti-interleukin 1 agents appear to be effective in refractory forms of the syndrome, although no controlled studies are available $22,23,24,25,26$

The main limitation of our single-center study is its retrospective design that precludes a precise evaluation of the treatment efficacy. Using the visual analog scale for assessing pain intensity would be helpful and should be included in future studies.

In our experience, advanced age was not a sufficient reason to rule out the diagnosis. SAPHO was not associated with HLA-B27. Soft tissue involvement was common, suggestive of infection or tumor, and explaining the nerve root pain. In contrast to antibiotics, pamidronate was consistently effective on bone involvement.

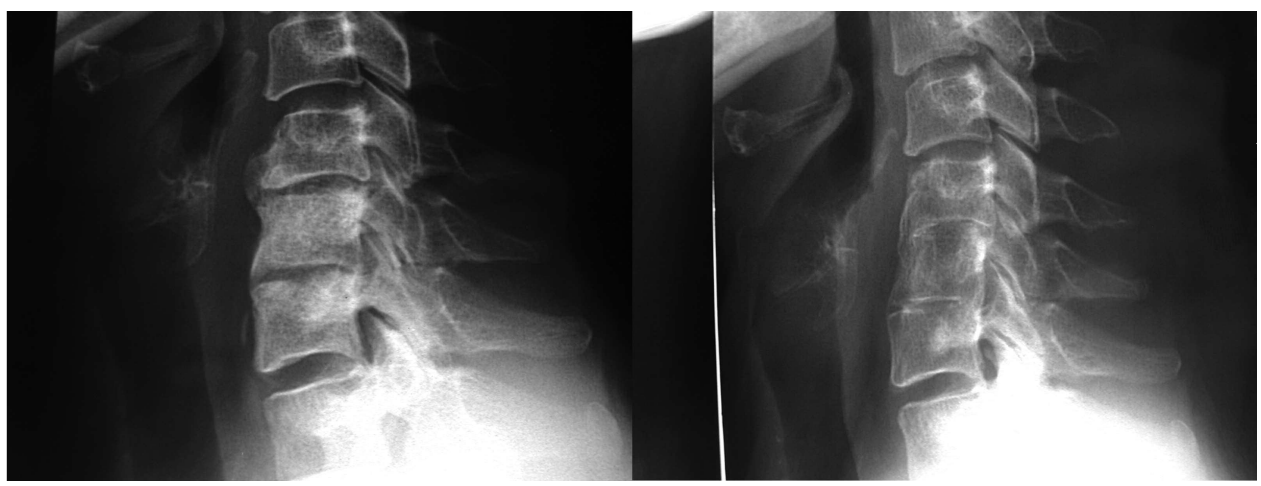

Figure 5. Cervical spine radiographs 8 years apart. Formation of a C4-C6 cervical block. 


\section{REFERENCES}

1. Chamot AM, Benhamou CL, Kahn MF, Beraneck L, Kaplan G, Prost A. [Acne-pustulosis-hyperostosis-osteitis syndrome. Results of a national survey. 85 cases]. [Article in French] Rev Rhum Mal Osteoartic 1987;54:187-96.

2. Nguyen MT, Borchers A, Selmi C, Naguwa SM, Cheema G, Gershwin ME. The SAPHO syndrome. Semin Arthritis Rheum 2012;42:254-65.

3. Hayem G, Bouchaud-Chabot A, Benali K, Roux S, Palazzo E, Sibermann-Hoffman O, et al. SAPHO syndrome: a long-term follow-up study of 120 cases. Semin Arthritis Rheum 1999; 29:159-71.

4. Colina M, Govoni M, Orzincolo C, Trotta F. Clinical and radiologic evolution of synovitis, acne, pustulosis, hyperostosis, and osteitis syndrome: a single center study of a cohort of 71 subjects. Arthritis Rheum 2009;61:813-21.

5. Sallés M, Olivé A, Perez-Andres R, Holgado S, Mateo L, Riera E, et al. The SAPHO syndrome: a clinical and imaging study. Clin Rheumatol 2011;30:245-9.

6. Benhamou CL, Chamot AM, Kahn MF. Synovitis-acne-pustulosis-hyperostosis-osteomyelitis syndrome (SAPHO). A new syndrome among the spondyloarthropathies? Clin Exp Rheumatol 1988;6:109-12.

7. Parlier-Cuau C, Laredo J. [Vertebral involvement in SAPHO syndrome]. [Article in French] J Radiol 2010;91:1068-78.

8. Mann B, Shaerf DA, Sheeraz A, Skinner JA, Saifuddin A. SAPHO syndrome presenting as widespread bony metastatic disease of unknown origin. Rheumatol Int 2012;32:505-7.

9. Kahn MF, Khan MA. The SAPHO syndrome. Baillieres Clin Rheumatol 1994;8:333-62.

10. Hayem G. Valuable lessons from SAPHO syndrome. Joint Bone Spine 2007;74:123-6.

11. Sonozaki H, Mitsui H, Miyanaga Y, Okitsu K, Igarashi M, Hayashi $\mathrm{Y}$, et al. Clinical features of 53 cases with pustulotic arthro-osteitis. Ann Rheum Dis 1981;40:547-53.

12. Govoni M, Colina M, Massara A, Trotta F. "SAPHO syndrome and infections". Autoimmun Rev 2009;8:256-9.

13. Assmann G, Kueck O, Kirchhoff T, Rosenthal H, Voswinkel J, Pfreundschuh M, et al. Efficacy of antibiotic therapy for SAPHO syndrome is lost after its discontinuation: an interventional study. Arthritis Res Ther 2009;11:R140.
14. Maugars Y, Berthelot JM, Ducloux JM, Prost A. SAPHO syndrome: a follow-up study of 19 cases with special emphasis on enthesitis involvement. J Rheumatol 1995;22:2135-41.

15. Queiro R, Moreno P, Sarasqueta C, Alperi M, Riestra JL, Ballina J. Synovitis-acne-pustulosis-hyperostosis-osteitis syndrome and psoriatic arthritis exhibit a different immunogenetic profile. Clin Exp Rheumatol 2008;26:125-8.

16. Grosjean C, Hurtado-Nedelec M, Nicaise-Roland P, Ferreyra-Dillon $\mathrm{R}$, Bollet C, Quintin E, et al. Prevalence of autoantibodies in SAPHO syndrome: a single-center study of 90 patients. J Rheumatol 2010;37:639-43.

17. Carneiro S, Sampaio-Barros PD. SAPHO syndrome. Rheum Dis Clin N Am 2013;39:401-18.

18. Guignard S, Job-Deslandre C, Sayag-Boukris V, Kahan A. Pamidronate treatment in SAPHO syndrome. Joint Bone Spine 2002;69:392-6.

19. Amital H, Applbaum YH, Aamar S, Daniel N, Rubinow A. SAPHO syndrome treated with pamidronate: an open-label study of 10 patients. Rheumatology 2004;43:658-61.

20. Colina M, La Corte R, Trotta F. Sustained remission of SAPHO syndrome with pamidronate: a follow-up of fourteen cases and a review of the literature. Clin Exp Rheumatol 2009;27:112-5.

21. Solau-Gervais E, Soubrier M, Gerot I, Grange L, Puechal X, Sordet $\mathrm{C}$, et al. The usefulness of bone remodelling markers in predicting the efficacy of pamidronate treatment in SAPHO syndrome. Rheumatology 2006;45:339-42.

22. Wagner AD, Andresen J, Jendro MC, Hülsemann JL, Zeidler H. Sustained response to tumor necrosis factor alpha-blocking agents in two patients with SAPHO syndrome. Arthritis Rheum 2002;46:1965-8.

23. Eleftheriou D, Gerschman T, Sebire N, Woo P, Pilkington CA, Brogan PA. Biologic therapy in refractory chronic non-bacterial osteomyelitis of childhood. Rheumatology 2010;49:1505-12.

24. Ben Abdelghani K, Dran DG, Gottenberg JE, Morel J, Sibilia J, Combe B. Tumor necrosis factor-alpha blockers in SAPHO syndrome. J Rheumatol 2010;37:1699-704.

25. Massara A, Cavazzini PL, Trotta F. In SAPHO syndrome anti-TNF-alpha therapy may induce persistent amelioration of osteoarticular complaints, but may exacerbate cutaneous manifestations. Rheumatology 2006;45:730-3.

26. Wendling D, Prati C, Aubin F. Anakinra treatment of SAPHO syndrome: short-term results of an open study. Ann Rheum Dis 2012;71:1098-100. 